\title{
Use of patient-generated health data for shared decision-making in the clinical environment: ready for prime time
}

\author{
Carolyn Petersen \\ Division of Biomedical Statistics and Informatics, Mayo Clinic, Rochester, MN, USA \\ Correspondence to: Carolyn Petersen. Division of Biomedical Statistics and Informatics, Mayo Clinic, 200 First St. SW, Rochester, MN 55905, USA. \\ Email: petersen.carolyn@mayo.edu. \\ Comment on: Lavallee DC, Lee JR, Austin E, et al. mHealth and patient generated health data: stakeholder perspectives on opportunities and barriers \\ for transforming healthcare. mHealth 2020;6:8.
}

Received: 02 March 2020; Accepted: 18 March 2020; Published: 20 July 2021.

doi: $10.21037 /$ mhealth.2020.03.05

View this article at: http://dx.doi.org/10.21037/mhealth.2020.03.05

Connected care is becoming established as a legitimate and effective way to provide many types of care (1). Models of connected care increasingly use patient-generated health data (PGHD) as a means by which patients and their care team can work together to improve both quality of care and quality of life (2). Workflows that enable the management of chronic conditions in ways that are more acceptable to patients and their care teams are needed, and PGHDmediated approaches may hold potential. For example, in-home remote monitoring via a telehealth system can alert providers to ineffective management of congestive heart failure and chronic obstructive pulmonary disease, allowing them to adjust patients' medications or care before hospitalization is needed (3). Motion detectors can report the lack of movement within the home that may signal a fall or other health problem, allowing individuals to remain independent and in their homes (4). Social media content has been shown to accurately reflect treatment practices in cancer (5). PGHD also have a role in the diagnosis of health conditions (6).

Use of PGHD offers an opportunity to facilitate connected care and expand the range of services and support that may be offered (7). However, there are no standards for use of PGHD, and to date numerous barriers to its use have been significant, including reliability of the data generated by personal devices (8); privacy and security concerns related to data collection, transmission, and storage (2); the potential for liability associated with providers' acceptance of PGHD from patients (9); and whether individuals will consistently use data generated by consumer-grade devices to achieve health goals $(10,11)$.

In their investigation of PGHD in mobile Health applications, Lavallee and colleagues shed light on the needs, goals, and concerns of patients and providers with experience using PGHD in routine care, as well as healthcare administrators. Through interviews with 41 patients, care team members, and administrators, the authors identify key considerations for the use of PGHD in clinical practice and put forward principles to support effective use of PGHD in clinical practice. Their work extends the field in several important ways.

First, this work supports the idea that individuals who proactively use tools to generate personal health data are intentional about data collection and sharing with providers and have specific purposes in mind for these data, and that this data collection and sharing support the health goals and health-sustaining practices of users. In particular, people who create and share PGHD do so as a way to more efficiently use their limited face-to-face time with clinicians. Some patients so prefer this approach to care that they seek out providers who are comfortable using PGHD in shared decision making. From the provider perspective, incorporation of PGHD into care pathways improves patient engagement and permits a better understanding of patients' health outside the clinic.

Next, the study elicits how use of PGHD supports and drives improved care when PGHD collection is aligned with measurement-based care. The collection, sharing, and review of PGHD by partnered patients and providers not only support improved patient outcomes, but also facilitate 
patient engagement and proactive involvement in healthpromoting activities. Too, providers find that individuals who manage their health using devices that create PGHD are less prone to reporting what they believe providers want to hear and less likely to be affected by stigma associated with difficult-to-discuss topics.

Lavallee and colleagues' work identifies positive and negative unintended consequences of PGHD that merit further study. Individuals who collect PGHD may be motivated to adopt healthier practices, find social support, or build confidence in their ability to manage their health. However, they may also be subject to anxiety or stress, and relationships with family members and friends may change.

This work delineates the impact that a lack of standards related to PGHD collection and sharing has on care in the clinical environment. Individuals have many choices in terms of the devices they use and the data they collect, and management of their data across platforms and systems remains a barrier to use of PGHD. Providers, too, struggle with the broad range of data types, formats, and interfaces, and will be even more challenged to effectively use PGHD as healthcare becomes increasingly personalized. Until standards are implemented across devices and clinical systems (e.g., electronic health records), the potential for PGHD to enhance care will remain unrealized.

Finally, this work reinforces the need to address barriers to implementation of PGHD use identified in previous work. Alignment with health system goals, selection of appropriate devices and types of data, training in effective PGHD use, and lack of reimbursement remain significant challenges for administrators. Until these challenges are resolved, routine PGHD use will be difficult to integrate into clinical workflows.

Efforts to understand patients' views about their goals and expectations are becoming standard in health services research. However, in much work patients are often an afterthought, or included as a token presence, even in investigations that seek to be patient-centered or inclusive of the patient perspective. It is heartening to see researchers include equal proportions of patient/caregiver and healthcare provider/administrator participants in this research.

With the shift to a healthcare system that makes greater use of digital tools and digitally facilitated strategies comes a need for a more nuanced understanding of patients' and providers' needs and goals, as well as the concerns of health system administrators charged with supporting a systemwide digital platform. In this work, Lavallee and colleagues have expanded the field's understanding of key considerations underlying the use of PGHD in primary care and laid a foundation for development of patient-centered, PGHD-mediated digital care.

\section{Acknowledgments}

Funding: None.

\section{Footnote}

Provenance and Peer Review: This article was commissioned by the editorial office, mHealth. The article did not undergo external peer review.

Conflicts of Interest: The author has completed the ICMJE uniform disclosure form (available at http://dx.doi. org/10.21037/mhealth.2020.03.05). The author has no conflicts of interest to declare.

Ethical Statement: The author is accountable for all aspects of the work in ensuring that questions related to the accuracy or integrity of any part of the work are appropriately investigated and resolved.

Open Access Statement: This is an Open Access article distributed in accordance with the Creative Commons Attribution-NonCommercial-NoDerivs 4.0 International License (CC BY-NC-ND 4.0), which permits the noncommercial replication and distribution of the article with the strict proviso that no changes or edits are made and the original work is properly cited (including links to both the formal publication through the relevant DOI and the license). See: https://creativecommons.org/licenses/by-nc-nd/4.0/.

\section{References}

1. Sayeed R, Gottlieb D, Mandl KD. SMART Markers: Collecting Patient-Generated Health Data as a Standardized Property of Health Information Technology. NPJ Digit Med 2020;3:9.

2. Cohen DJ, Keller SR, Hayes GR, et al. Integrating Patient-Generated Health Data Into Clinical Care Settings or Clinical Decision-Making: Lessons Learned From Project HealthDesign. JMIR Hum Factors 2016;3:e26.

3. Gokalp H, de Folter J, Verma V, et al. Integrated Telehealth and Telecare for Monitoring Frail Elderly with Chronic Disease. Telemed J E Health 2018;24:940-57. 
4. Rantz M, Skubic M, Abbott C, et al. Automated In-Home Fall Risk Assessment and Detection Sensor System for Elders. Gerontologist 2015;55 Suppl 1:S78-87.

5. McDonald L, Behl V, Sundar V, et al. Validity of social media for assessing treatment patterns in oncology patients: a case study in melanoma. JAMIA Open 2019;2:416-22.

6. Sawyer RG, Evans HL, Hedrick TL. Technological Advances in Clinical Definition and Surveillance Methodology for Surgical Site Infection Incorporating Surgical Site Imaging and Patient-Generated Health Data. Surg Infect (Larchmt) 2019;20:541-5.

7. Purswani JM, Dicker AP, Champ CE, et al. Big Data From Small Devices: The Future of Smartphones in Oncology. Semin Radiat Oncol 2019;29:338-47.

doi: $10.21037 /$ mhealth.2020.03.05

Cite this article as: Petersen C. Use of patient-generated health data for shared decision-making in the clinical environment: ready for prime time. mHealth 2021;7:39.
8. Khosla S, Deak MC, Gault D, et al. Consumer Sleep Technology: An American Academy of Sleep Medicine Position Statement. J Clin Sleep Med 2018;14:877-80.

9. Petersen C, DeMuro P. Legal and regulatory considerations associated with use of patient-generated health data from social media and mobile health (mHealth) devices. Appl Clin Inform 2015;6:16-26.

10. Park YR, Lee Y, Kim JY, et al. Managing PatientGenerated Health Data Through Mobile Personal Health Records: Analysis of Usage Data. JMIR Mhealth Uhealth 2018;6:e89.

11. Reading M, Baik D, Beauchemin M, et al. Factors Influencing Sustained Engagement with ECG SelfMonitoring: Perspectives from Patients and Health Care Providers. Appl Clin Inform 2018;9:772-81. 